\title{
SOLIDARIEDADE NA PANDEMIA DA COVID-19: \\ ESTRATÉGIAS DE RESISTÊNCIA DO \\ MOVIMENTO DOS TRABALHADORES \\ SEM-TETO (MTST)
}

SOLIDARITY IN COVID-19'S PANDEMIC: STRATEGIES OF RESISTANCE FROM THE HOMELESS WORKERS MOVEMENT (MTST)

\section{Luisa Souto}

Doutoranda em Sociologia do Programa de Pós-graduação em Ciências Sociais da Pontifícia Universidade Católica do Rio de Janeiro (PPGCIS/PUC-Rio) e em Sciences Politiques et Sociales do Centre de Recherches Interdisciplinaires "Démocratie, Institutions, Subjectivité" (CriDIS) da Université Catholique de Louvain (UCLouvain). 


\section{RESUMO}

Considerando a intensidade da crise relativa à pandemia da Covid-19 no mundo, em especial nas periferias das cidades, este artigo se debruça sobre as ações de solidariedade desenvolvidas pelo Movimentos dos Trabalhadores Sem-Teto (MTST) para com os militantes da base social do movimento e as comunidades que residem no entorno das ocupações em diferentes territórios brasileiros. Ação política coletiva, cooperação e empatia se encontram no necessário espaço do cuidado que se mostrou ainda mais indispensável para a sobrevivência da população. Diante do aumento dos índices de fome e insegurança alimentar, a criação de cozinhas solidárias como forma de lutar pelo direito à alimentação ganha destaque no contexto atual.

Palavras-chave: Covid-I9; movimentos sociais; solidariedade; cozinhas coletivas.

\section{ABSTRACT}

Considering the intensity of the crisis related to the Covid-I9 pandemic in the world, especially in the peripheries of cities, this article focuses on the solidarity actions developed by the Movements of the Homeless Workers (MTST) towards the militants of the social base of the movement and the communities that live around the occupations in different Brazilian territories. Collective political action, cooperation and empathy are found in the necessary space of care that has proved to be even more indispensable for the population's survival. In view of the increase in hunger and food insecurity rates, the creation of solidarity kitchens as a way to fight for the right to food is highlighted in the current context.

Keywords: Covid-19; social movements; solidarity; collective kitchens. 
"Do que eu mais tenho medo neste momento? Dos meus filhos passarem fome."

(Celly Gomes, militante do MTST/RJ)

\section{Introdução}

Como observado no último ano, a pandemia da Covid-I9 abalou as estruturas de boa parte da sociedade contemporânea, provocando picos de infecção que fizeram com que diversos países se encontrassem inseridos num ciclo ainda sem previsão de fim de acirramento da pandemia, o que permitiria relaxamento das medidas de isolamento social, de acordo com os números de pessoas infectadas e de mortes. Embora as campanhas de imunização já aconteçam em parte do mundo, esta segue a passos lentos em parte considerável do planeta, seja por insuficiência de imunizantes, seja por questões culturais e políticas. Ainda que em contextos diferentes, é inegável a intensidade com que as consequências econômicas e sociais da pandemia impactam negativamente a vida de pessoas de diferentes estratos sociais.

Como aponta David Harvey (2020), há um mito conveniente de que as doenças infecciosas não reconhecem classe social ou outras barreiras e fronteiras sociais. Mostrando o contrário, o progresso da Covid-I9 evidencia cada vez mais as características e as decorrências de uma pandemia de classe, gênero e raça. Há uma parcela da classe trabalhadora que apresenta maior risco de contrair o vírus, seja por que não pode se afastar do trabalho, seja por que é demitida por conta das medidas de contenção econômica, ou por que, no mais das vezes, trabalha em situação de precariedade.

Este artigo $^{1}$ busca apresentar algumas ações realizadas pelos movimentos sociais, aqui especificamente o Movimento dos Trabalhadores Sem-teto (MTST), desde o início da pandemia, no contexto da luta por direitos da classe trabalhadora e na tentativa de minimizar os danos causados pela crise sanitária e social.

\section{Breve contexto}

Mais de um ano após a chegada da pandemia da Covid-ı no Brasil, para além dos cada vez mais assustadores números de contaminados e mortos pelo vírus, pesquisas sobre aspectos socioeconômicos sob influência da crise estão sendo realizadas e construindo o cenário social no qual estamos inseridos. Além dos dados da Pesquisa

\footnotetext{
${ }^{1}$ Este artigo foi escrito a partir de dados colhidos no âmbito da pesquisa de doutorado, Solidariedade e luta no mundo contemporâneo: cotidiano e cuidado no Movimento dos Trabalhadores Sem-teto. As imagens foram extraídas dos sites www.mtst.org e www.instagram.com/mtstbrasil, e fazem parte do acervo do movimento.
} 
Nacional por Amostra de Domicílios Contínua do Instituto Brasileiro de Geografia e Estatísticas (PNAD/IBGE), ${ }^{2}$ que apontam que, entre setembro e dezembro de 2020, o Brasil contabilizou I4,I milhões de desempregados, chamam atenção as investigações acerca da questão da alimentação no país durante esse período. Dados do Inquérito Nacional sobre Insegurança Alimentar no Contexto da Pandemia da Covid-I9 no Brasil, conduzido pela Rede Brasileira de Pesquisa em Soberania e Segurança Alimentar e Nutricional (PENSSAN), a fome atingiu I9 milhões de brasileiros em 2020. ${ }^{3}$ A pesquisa "Efeitos da pandemia na alimentação e na situação da segurança alimentar no Brasil",4 coordenada pelo Grupo de Pesquisa Alimento para Justiça da Universidade Livre de Berlim, na Alemanha, em parceria com a Universidade Federal de Minas Gerais (UFMG) e com a Universidade de Brasília (UnB), mostra que mais da metade dos domicílios no país $(59,4 \%)$ apresentaram algum grau de insegurança alimentar entre agosto e dezembro de 2020.

Há um duplo dilema exposto no contexto da crise provocada pela pandemia da Covid19: ao mesmo tempo que exige das pessoas o máximo de isolamento possível para frear os índices de contaminação, o vírus expõe de maneira radical as desigualdades e a dependência uns dos outros; a necessidade das interações e relações sociais. Os cidadãos dependem do governo e das políticas públicas. Dependem do bom funcionamento do sistema de saúde, tanto público quanto privado. Dependem de condições básicas de higiene e saneamento. Dependem do funcionamento de serviços básicos como supermercados e farmácias. Dependem uns dos outros. Nas palavras de Flavia Biroli (2020a), "o coronavírus joga luz sobre a inevitável interdependência entre os seres humanos". Uma pessoa que faz todo o necessário para se proteger do vírus, só está protegida se o vizinho, o familiar, aquele que está próximo, também o fizer. Alguns só podem se alimentar se receberem alimentos. Outros perdem suas fontes de renda e dependem da ação do governo para sobreviver, o que, como mencionado, se deu (e assim segue) de maneira problemática e limitada. No Brasil, depois de uma primeira fase de distribuição do Auxílio Emergencial no valor de $\mathrm{R} \$ 600,00$, o programa foi retomado, mas no valor de $\mathrm{R}$ \$ 150,00, o que não garante aos que dele dependem a possibilidade de se alimentar de maneira satisfatória.

Se a marca da sociedade que se desenvolve sob a lógica do capitalismo é um processo constante de erosão dos laços de solidariedade e uma sociabilidade individualista, com a

\footnotetext{
${ }^{2}$ Disponível em: <https://agenciadenoticias.ibge.gov.br/agencia-noticias/2012-agencia-de-noticias/noticias/29782-numero-dedesempregados-chega-a-14-1-milhoes-no-trimestre-ate-outubro>. Acesso em: 01 abr. 2021.

${ }^{3}$ A pesquisa foi realizada durante os dias 5 e 24 de dezembro, em 2.180 domicílios nas cinco regiões do Brasil, questionando os moradores sobre os três meses anteriores ao momento coleta. Fonte: <http://olheparaafome.com.br/>.

${ }^{4}$ Pesquisa realizada em novembro e em dezembro de 2020, e divulgada em 13 abr. 2021. Cerca de duas mil pessoas fizeram parte da amostra. Fonte: <https://www.lai.fu-berlin.de/pt/forschung/food-for-justice/publications1/Publikationsliste_WorkingPaper-Series/Working-Paper-4/index.html>.
} 
crise da Covid-ı9 ficou evidente como é importante a reconstrução e a manutenção de laços que permitam aos seres humanos cuidar e serem cuidados.

São muitas as iniciativas no país que podem ser citadas, principalmente se nos referirmos ao ano passado. Como era de se esperar, algumas delas, com o passar do tempo, foram se enfraquecendo diante das dificuldades enfrentadas e de um cansaço generalizado na população. Mas em 202I, com o agravamento da situação sanitária e social, alguns grupos tentam se reorganizar para seguir com a ajuda.

Neste artigo, serão apresentados alguns aspectos da atuação do Movimento dos Trabalhadores Sem-Teto (MTST), um dos principais movimentos sociais urbanos da atualidade, diante da crise social que impacta a cada dia nos problemas sociais existentes no país. Atualmente, o movimento está organizado em onze estados da federação, reunindo em sua base social mais de cinquenta mil famílias espalhadas por ocupações, acampamentos e núcleos comunitários. Diante da amplitude do alcance do movimento, este artigo não pretende dar conta de todas as ações empreendidas, mas sim apontar algumas importantes iniciativas que foram ou continuam sendo realizadas.

De modo geral, cabe dizer que o segmento dos sem-teto abrange uma população trabalhadora de baixa remuneração, no mercado informal ou desempregada, como definiu, em informação verbal, Fabiana Batista, militante do MTST do Rio de Janeiro: "nossa base é composta por pessoas que trabalham em supermercados, garis, empregadas domésticas e pessoas que vivem de 'bico' para sobreviver". No mesmo caminho, Jussara Basso, coordenadora da ocupação Vila Nova Palestina, ${ }^{5}$ em São Paulo, aponta que a base social do MTST é composta por trabalhadores com uma renda de até três saláriosmínimos, precarizados, que fazem parte de famílias numerosas e, principalmente, mães solteiras com mais de três filhos. ${ }^{6}$ Assim, compõem a parcela da sociedade que é fatalmente atingida por qualquer crise.

Os movimentos sociais, de modo geral, se viram diante de um grande desafio no início de 2020. As necessárias medidas de distanciamento social impostas para tentar conter o avanço da Covid-ı9 na metade do primeiro semestre, colocaram em suspenso ações que haviam sido planejadas para o período, como parte das estratégias de enfrentamento aos graves retrocessos nos investimentos nas políticas de habitação desde o impeachment da presidenta Dilma Rousseff. O MTST se preparava para uma nova onda de ocupações em terrenos ociosos, principalmente nas periferias da cidade. Com a pandemia, o plano se tornou inviável e teve que ser adiado. Além disso, a precária situação de sua base social e

\footnotetext{
${ }^{5}$ A Ocupação Vila Nova Palestina abrange uma área de 100 hectares, e é uma das maiores ocupações urbanas da América Latina.

${ }^{6}$ Informação disponível em: <http://mapadeconflitos.ensp.fiocruz.br/conflito/sp-ocupacao-vila-nova-palestina-luta-pormoradia-digna-e-direitos-constitucionais/>. Acesso em: 10 jan. 2021.
} 
o rápido agravamento das desigualdades se apresentaram como um chamado à busca de outras formas de atuação. Sem pretender fazer da necessidade uma virtude, é preciso observar que as limitações impostas pela pandemia fizeram surgir no movimento propostas importantes. "Novas estratégias contra velhas barbáries", é o título de um dos primeiros textos sobre a conjuntura publicado no site do movimento.

Movimentos sociais, de acordo com Ilse Scherer-Warren(2OI2), são redes sociais que se conectam de forma não apenas física, mas simbólica, solidária e estratégica. No caso do MTST, a tática da ação política impulsionada pela solidariedade, que compõe o repertório de ação tradicional do movimento, precisou ser revista, intensificada e expandida. As redes internas precisaram ser fortalecidas e as externas, ativadas. Desde os primeiros meses, o movimento voltou suas decisões políticas e a ação da militância para o combate aos efeitos da pandemia nos territórios em que está presente através de práticas solidárias que visam tornar possível a sobrevivência daqueles que têm menos ou nenhum acesso aos recursos básicos necessários.

\section{"Movimento social fazendo o que o governo não faz"s}

Em termos práticos, entre as ações estão a arrecadação de alimentos, produtos de higiene pessoal e limpeza para distribuição de cestas básicas; a organização de uma cooperativa de costureiras para produção de máscaras de proteção pessoal; disponibilização de álcool em gel em ocupações e acampamentos; ações da Brigada de Arquitetura orientando como manter a proteção dentro de casa; e intensificação das atividades nas cozinhas solidárias.

A primeira campanha de arrecadação de fundos pela internet, iniciada em I9 de março de 2020, denominada "Fundo emergencial para os sem-teto afetados pelo coronavírus", se estendeu por diversos meses e teve seis etapas. Ao todo, foram arrecadados R\$ I.247.088,3I. ${ }^{9}$ A organização contou com a colaboração de parceiros no Brasil e mobilizou também redes internacionais de solidariedade. Garantiu condições financeiras para que o movimento pudesse atuar não apenas no suporte aos militantes da base, mas também estabelecer redes solidárias com os moradores das periferias no entorno de ocupações e acampamentos e com outros movimentos sociais, e desenvolver ações junto aos moradores de rua. Estima-se que nessa primeira fase, o MTST tenha conseguido ajudar mais de 20 mil famílias com a distribuição de centenas de milhares de

\footnotetext{
${ }^{7}$ Informação disponível em: <https://mtst.org/mtst/cestas-basicas-em-vez-de-ocupacoes-o-mtst-em-tempos-de-coronanovas-estrategias-contra-velhas-barbaries/>. Acesso em: 10 mar. 2021.

${ }^{8}$ Lema que o MTST adotou para caracterizar suas ações durante a pandemia.

${ }^{9}$ Para acessar o site da campanha: <https://www.vakinha.com.br/vaquinha/ajude-os-sem-teto-a-enfrentar-o-coronavirus>.
} 
cestas básicas, kits de higiene, kits para gestantes, máscaras, álcool em gel e outros itens básicos. Em IO de janeiro de 202I, diante da persistente necessidade da população, foi lançada uma nova campanha de solidariedade, dessa vez sob o título "Fundo de solidariedade para as famílias sem-teto" e com uma meta menor. Ao todo, foram arrecadados R\$226.17I,00.

Na cidade de São Paulo, o apoio aos moradores de rua foi realizado em conjunto com a Pastoral Povo de Rua, conhecida pela figura do padre Júlio Lancelotti, que promove a distribuição de alimentos, chá e conversas (ver Figura I). Uma ação importante que alcança um grupo extremamente vulnerável que não pode atender à primeira regra de proteção contra o vírus: ficar em casa. No ABC Paulista, diversos militantes do movimento também se organizaram para distribuição de marmitas a essa parcela da população comumente invisibilizada e marginalizada.

Figura 1. Distribuição de alimentos para a população em situação de rua em São Paulo.

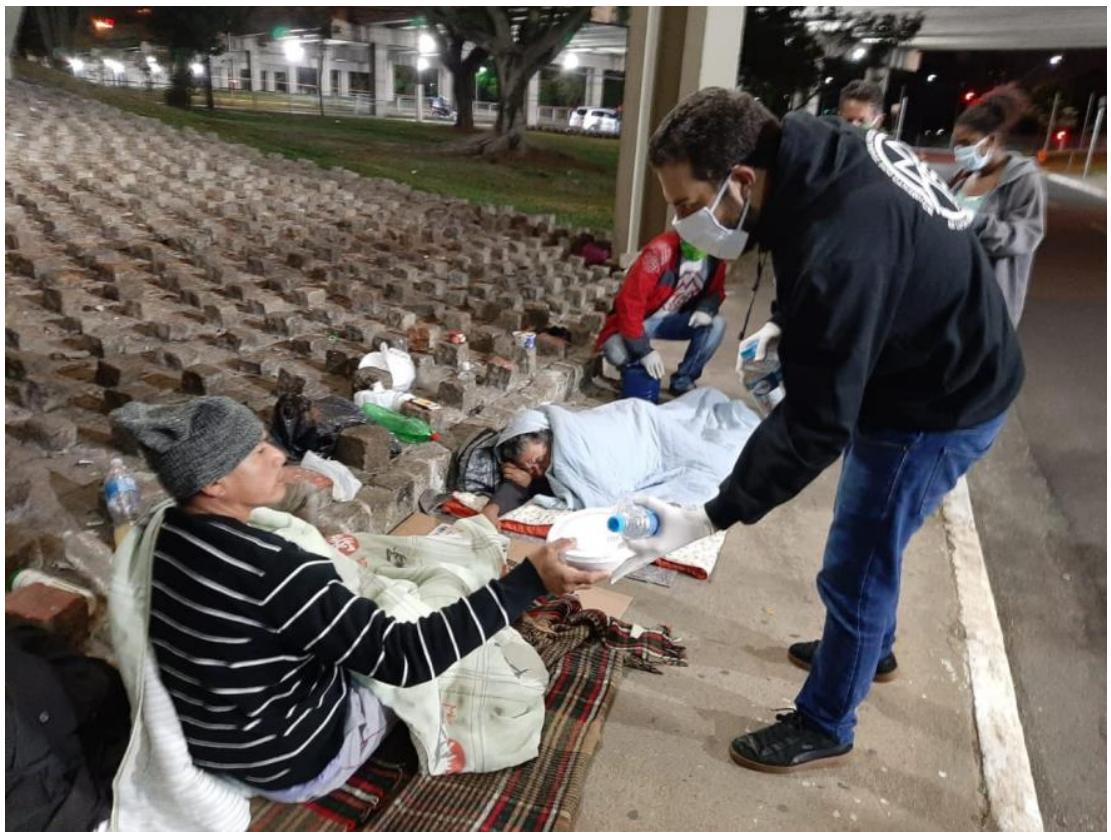

Foto: Acervo MTST (2020). 
A Brigada de Arquitetura do movimento elaborou, em maio de 2020, uma campanha com orientações para as pessoas se protegerem do vírus dentro de casa e nos espaços coletivos das ocupações. ${ }^{10}$ A ação promoveu a divulgação, via internet, de uma série de cards (ver Figura 2) que abordam formas de prevenção do contágio dentro de moradias de um único cômodo, passando pela higienização e pelo cuidado com as pessoas que residem nesses espaços; pela proteção em locais públicos, transportes coletivos e mercados; e dicas para higienização e armazenamento de produtos e alimentos. No caso dos espaços coletivos, orientava-se evitar aglomerações; utilizar máscaras para retirada das refeições nas cozinhas coletivas; redobrar os cuidados com a higiene nas cozinhas de uso comum; e limpeza e higienização diária dos banheiros coletivos, sempre reforçando que se os espaços forem frequentados por pessoas com suspeita de infecção, a limpeza deve ser feita pelo menos imediatamente após o uso.

Figura 2. Capas dos materiais da campanha da Brigada de Arquitetura.

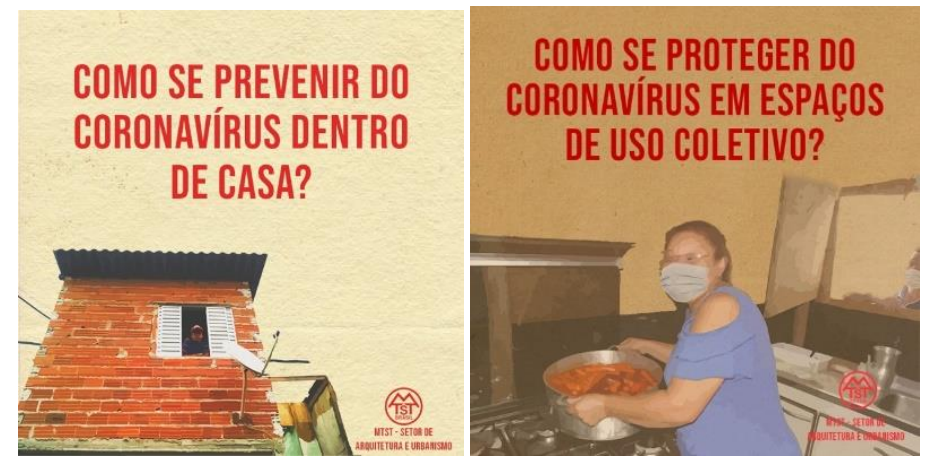

Fonte: Acervo MTST (2020).

Para a difusão dessas informações, foram fundamentais as redes sociais e os aplicativos de troca e transmissão de mensagens via celular. Outra ação que o movimento avaliou como urgente, e que facilitou a realização da campanha mencionada e de outras, foi o esforço para a articulação de uma rede de comunicação alternativa que pudesse passar aos militantes informações importantes, atualizar sobre a situação da pandemia e combater a disseminação de fake news, cada vez mais presentes no cotidiano da população. Em São Paulo, foi disponibilizado um número de telefone para divulgação de notícias e prestação de auxílio direto aos militantes. A disseminação de falsas notícias e o excesso de informação prejudica o tratamento em caso de contaminação e afeta a saúde mental das pessoas.

\footnotetext{
${ }^{10}$ Informação disponível em: <https://mtst.org/mtst/brigada-de-arquitetura-e-urbanismo-do-mtst-apoio-acolhida-e-cuidadoscom-a-saude-e-a-vida-das-familias/>. Acesso em: 10 mar. 2021.
} 
O Setor de Saúde do movimento, em parceria com o Núcleo de Estudos e Trabalhos Terapêuticos (NETT), organizou, a partir de maio de 2020, plantões de atendimento psicológico para todos aqueles que se sentiram impactados psicologicamente por consequências diretas da pandemia ou por todas as incertezas e medos que a acompanharam (ver Figura 3). Como conta a coordenadora do setor, Raisa Guimarães:

[...] muitas pessoas têm entrado em crises de ansiedade exacerbada e procuram um hospital achando se tratar de contaminação por Covid-I9, por alguns sintomas serem semelhantes. Pessoas têm desenvolvido processos de ansiedade, pânico e transtorno obsessivo-compulsivo (TOC), e procuram os atendimentos psicológicos do MTST em parceria com o NETT, que dá continuidade aos atendimentos. ${ }^{11}$

Outra preocupação era com os impactos na população LGBT, altamente vulnerabilizada.

Figura 3. Setor de Saúde do MTST atua debaixo da lona preta nas ocupações.

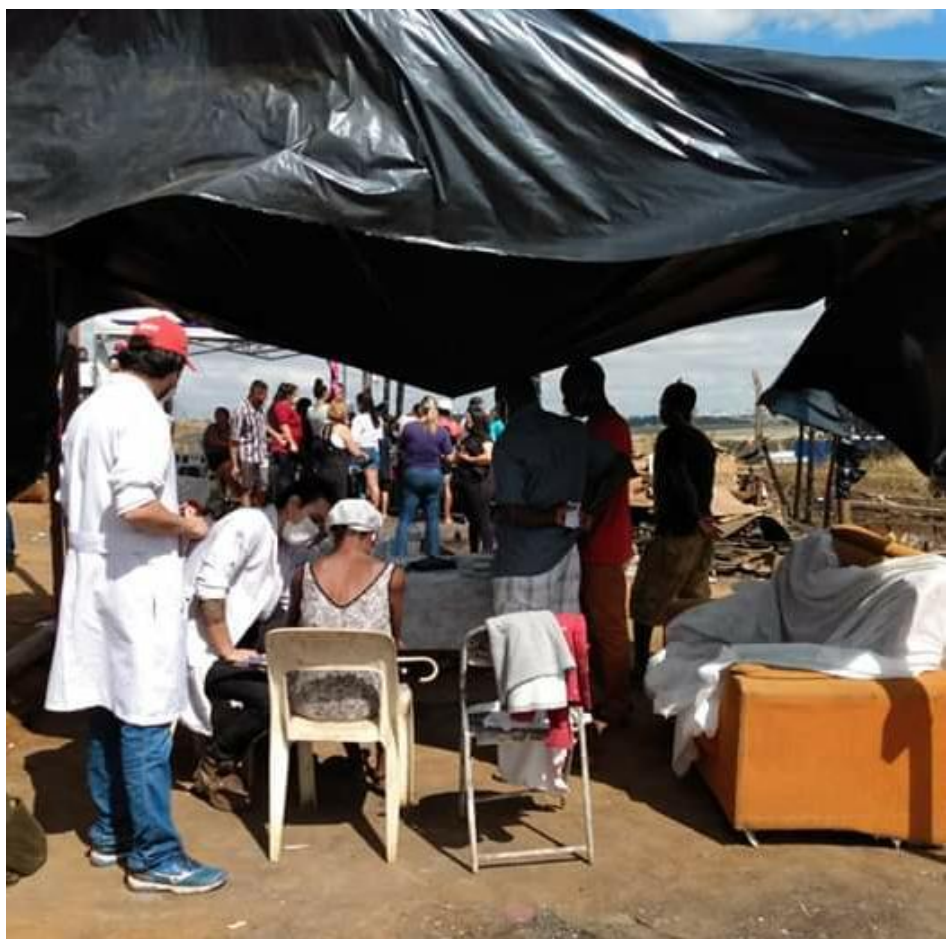

Foto: Acervo MTST (2020).

Em diversos territórios, a partir de abril de 2020 , foram organizadas cooperativas de costureiras com as militantes do movimento para a produção de máscaras de proteção

\footnotetext{
${ }^{11}$ Informação disponível em:<https://mtst.org/mtst/mtst-cuida-da-saude-mental-dos-sem-teto-em-tempos-de-pandemia/>. Acesso em: 01 abr. 2021.
} 
contra o vírus. Em menos de um mês, apenas na zona leste de São Paulo, já haviam sido produzidas e distribuídas mais de I.600 máscaras. Ao todo, estima-se que, até dezembro de 2020 , mais de IIO mil máscaras de proteção foram produzidas pelos sem-teto e distribuídas para a população.

Parte central do cotidiano do movimento são as cozinhas coletivas. É a primeira coisa a ser erguida no momento que se realiza uma nova ocupação, e o local no qual se vai produzir a comida que sustentará os militantes, além do espaço a partir do qual se organizará a base. Chamadas de coletivas ou comunitárias, a depender do local, são uma marca registrada do movimento. Ali se produzem, distribuem e consomem refeições, mas também se modulam muitas relações a partir de uma dinâmica que conjuga alimentação com solidariedade social e formação política. O fato de nas ocupações existir uma cozinha comunitária, que é abastecida coletivamente e serve a todos, conta Jussara Basso, é algo que reforça um sentimento distinto do individualismo e da competitividade presentes na sociedade em geral. O preparo de alimentos é central para a vida e a política, e não mais uma tarefa invisível. ${ }^{12}$ É nas cozinhas que os militantes se encontram diariamente, trocam informações e experiências e, antes da pandemia, eram também espaços de debates, rodas de conversas e atividades culturais. São várias as cozinhas que existem atualmente, e milhares os pratos e as quentinhas produzidos de modo conjunto e distribuídos semanalmente. Um texto publicado pelo movimento em 20I8, ao qual os militantes se referem ainda hoje, explica porque é comum ouvi-los dizer que "a cozinha é o coração da ocupação":

Mas "por que destacar logo a cozinha?", alguém poderia se perguntar. Porque, além de ser um ponto de referência do Movimento dos Trabalhadores Sem-teto, a cozinha comunitária se revela como "coração" para as pessoas que ali chegam. Muito além de um cafezinho, ali se encontra o aperto de mão, o abraço, a palavra companheira que fortaleceu a cada um que necessitou durante a vigília que havia sido iniciada. Um sustento físico, mas, principalmente, um sustento coletivo e partilhado de justiça social como exercício pleno de uma sociedade mais humana. Na lateral, os mantimentos e utensílios foram arrumados de maneira que, durante o revezamento, tudo fosse tranquilo. Arroz, feijão, macarrão, pães, suco, café, leite, água, produtos de higiene e limpeza são todos frutos da colaboração de pessoas que acreditam na

transformação social promovida pelo movimento e, dessa forma, o

\footnotetext{
12 Informação disponível em: <https://azmina.com.br/colunas/mulheres-negras-maes-trabalhadoras-a-linha-de-frente-do$\mathrm{mtst} />$. Acesso em: 10 abr. 2021.
} 
mesmo sentimento foi visto e sentido durante as horas de refeição: café da manhã, almoço e jantar. ${ }^{13}$

No contexto da pandemia, com o avanço da fome pelas periferias brasileiras e a fragilização da população, esse lugar que, de acordo com quem o constrói, tem o potencial de alimentar corpos e mentes dos indivíduos, se tornou ainda mais importante. Não apenas para a militância ou para os que vivem nas ocupações, mas para um número cada vez mais crescente de pessoas em necessidade. Nas palavras de militantes do movimento, "solidariedade para além das próprias fileiras". Um dos principais objetivos das campanhas de arrecadação coletiva de fundos, como as mencionadas anteriormente, era garantir o necessário para que as cozinhas pudessem continuar e crescer para dar conta da nova demanda. Além da intensidade, outras mudanças precisaram ser feitas para manter o funcionamento, garantindo a segurança dos responsáveis e colaboradores das cozinhas e daqueles que iam em busca de comida. Entre riscos e desafios, fechar não era uma opção, como conta Celly Gomes, da Cozinha Comunitária São Gonçalo/RJ: “As pessoas perguntam a semana toda sobre a cozinha, 'vai ter comida?'. Histórias não faltam e nem riqueza nelas, muitas pessoas dependem da cozinha e seria difícil fechar sabendo que tem tanta gente com fome lá fora". ${ }^{14}$

Em Uberlândia $(\mathrm{MG})$, por exemplo, cozinhas comunitárias mobilizam dezenas de militantes diariamente e, em parceria com a Comissão Pastoral da Terra e a Central de Movimentos Populares, têm capacidade para alimentar cerca de I.200 pessoas em diferentes bairros da periferia da cidade (ver Figura 4, esquerda). Outros movimentos, como o Movimento dos Trabalhadores Rurais Sem-terra (MST) e o Movimento dos Pequenos Agricultores (MPA), também compuseram essa rede de solidariedade entre movimentos sociais e ajudaram a abastecer as despensas de cozinhas em vários estados: "parceria entre a roça e a favela", como definiram os próprios militantes (ver Figura 4, direita).

\footnotetext{
${ }^{13}$ Informação disponível em: <https://mtst.org/mtst/resistencia-e-partilha-os-dias-em-que-a-cozinha-comunitaria-do-mtstdeu-forca-e-energia-para-a-resistencia-na-luta-por-lula-livre/>. Acesso em: 01 abr. 2021.

${ }^{14}$ Informação disponível em: <https://mtst.org/mtst/cozinha-comunitaria-do-mtst-em-sao-goncalo-juntos-sairemos-maisfortes/>. Acesso em: 01 abr. 2021.
} 
Figura 4. Esquerda: distribuição de quentinhas em uma cozinha coletiva de Uberlândia (MG); direita: mesa com alimentos recebidos pela parceria entre MTST e MPA, em São Gonçalo (RJ).
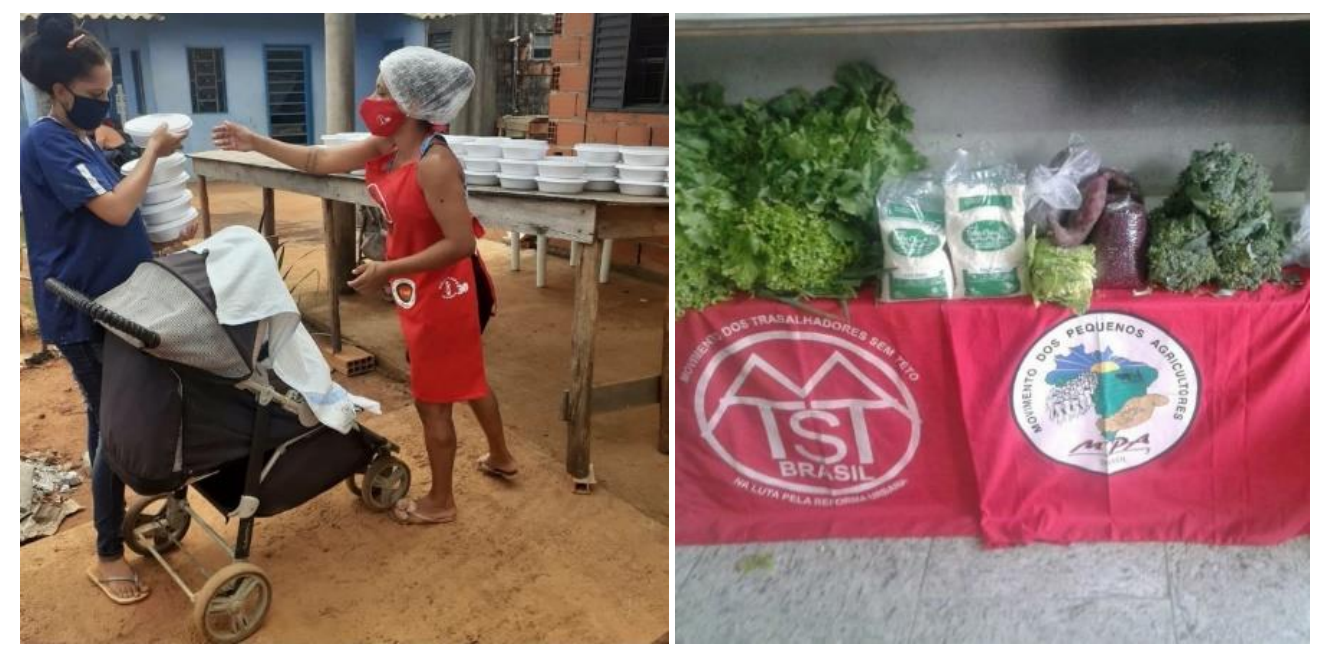

Fotos: Acervo MTST (2021).

Uliana Esteves (2020) propõe uma reflexão sobre a relação entre comida e solidariedade na pandemia à luz da noção de gastropolítica de Arjun Appadurai (I98I) que, a meu ver, serve para observar a dinâmica das cozinhas coletivas das ocupações e sua importância no momento atual. A comida, de acordo com Appadurai (I98I), faz parte de um sistema que, em contextos particulares, tem o potencial de articular dinâmicas de socialização com consequências imediatas e, em maior prazo, fins estruturais. Durante a pandemia, no campo das relações em torno da comida, o ato de alimentar a si mesmo e a outrem tem modulado a criatividade solidária dirigida a pessoas e populações afetadas pela crise. Preenche os pequenos espaços de relações possíveis quando o afastamento físico se faz necessário. E isso se dá a partir de uma necessidade imediata. Ficar em casa é uma ação de proteção que nem todos podem executar e, ainda que seja chocante, se alimentar, diante desse cenário, também não. Os marcadores sociais da diferença fazem com que as características da experiência da pandemia para cada um se deem de formas diferentes. É nesse sentido que as práticas solidárias em torno da comida, já historicamente valorosas diante $\mathrm{da}$ desigualdade social tradicional do país, desempenharam papel ainda mais relevante nesse momento, atuando na subsistência da população. É por isso que Esteves (2020) faz a conexão com a gastropolítica, dado que essas ações compõem um eixo voltado para a manutenção da vida que se contrapõe às insuficientes ações estatais, as quais classifica como "gramáticas de poder elaboradas, sistematicamente, em torno da morte" (p. 7). 


\section{Direito à alimentação como linha política prioritária do movimento}

No início de 202I, diante da persistência da crise e da falta de perspectiva de melhora da situação da fome no país, o movimento voltou seus esforços para a implementação de um projeto de expansão das cozinhas coletivas com intuito de tornar a prática da alimentação solidária uma política do movimento, tal qual a luta pela habitação. Assumem agora o nome de Cozinhas Solidárias. A iniciativa prevê a instalação de unidades em diversos territórios do país, e tem a população mais pobre das cidades como público-alvo. As cozinhas estarão na periferia dos estados de Roraima (ver Figura 5), Ceará, Pernambuco, Alagoas, Sergipe, Goiás, Minas Gerais, Rio de Janeiro, São Paulo e Rio Grande do Sul, bem como no Distrito Federal, e é possível que chegue a outros lugares.

\section{Figura 5. Cozinha Solidária em Roraima.}

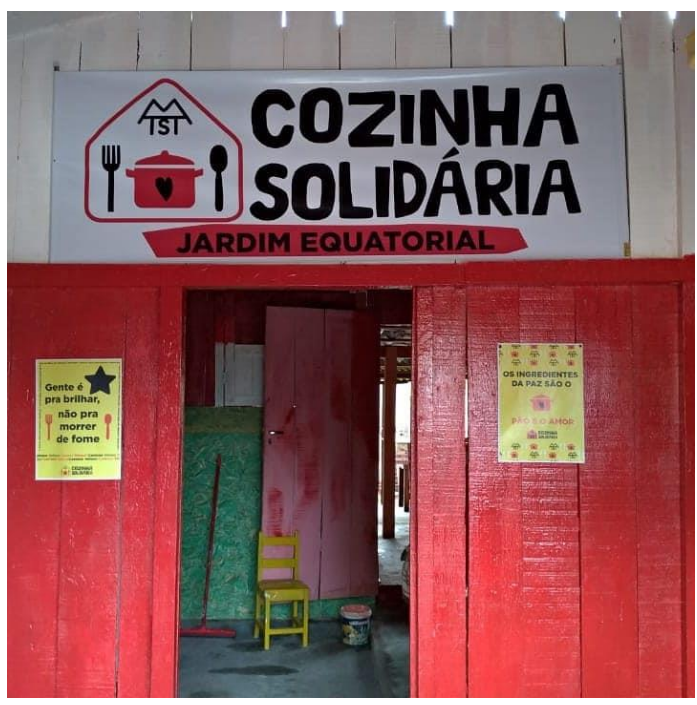

Foto: Acervo MTST (2021).

Para viabilizar o projeto, foi lançada uma campanha de financiamento coletivo pela internet voltada exclusivamente para as cozinhas. Além do dinheiro da campanha, o movimento espera poder contar também com parcerias com movimentos de agricultura familiar e comerciantes locais para formar o que chamam de "rede de abastecimento das cozinhas solidárias do MTST". O projeto, idealizado pelos sem-teto, surge como uma resposta à volta da fome nas comunidades, periferias e ocupações das cidades brasileiras. Guilherme Boulos, um dos líderes do movimento, contextualiza: "Temos hoje, junto com a pandemia da Covid-ı, uma epidemia de fome no Brasil causada pelo desemprego e pela inflação dos alimentos. Há muito tempo não se via um cenário de carestia tão grande". ${ }^{15}$ As cozinhas funcionarão todos os dias distribuindo café da manhã e almoço. Um dos

\footnotetext{
15 Informação disponível em: <https://www.brasildefato.com.br/2021/03/13/para-combater-pandemia-da-fome-mtstinaugura-cozinha-solidaria-em-sp>. Acesso em: 04 abr. 2021.
} 
principais objetivos é garantir que as famílias em vulnerabilidade tenham direito à alimentação saudável e com qualidade nutricional mesmo durante o período de crise.

A ideia, assim como nas cozinhas dos acampamentos, é que seja um espaço que ofereça aos indivíduos mais do que comida, mas também acolhimento, troca e auxílio nas demandas da população, que cada vez mais veem outras esferas da vida serem afetadas. Como me explicou Débora Pereira, do MTST de São Paulo:

O movimento tem pessoal da educação, tem jurídico, tem arquiteto, engenheiro, tem gente da saúde... Tem várias pessoas. Gente da cultura. E as nossas periferias são carentes de todas as políticas públicas, de educação, de saúde. Então a gente quer aproveitar essas pessoas que estão no MTST e querem contribuir, e que no ano passado não puderam contribuir mais por causa da pandemia. A gente quer aproveitar as cozinhas pra construir esse espaço. [...] Por exemplo, tem crianças que ficaram muito tempo sem estudar e estão precisando de aula de reforço. É pegar esses professores pra dar aula pra eles. Tem comunidade que é carente de atendimento de saúde... Não que a nossa equipe de saúde vá lá atender, mas o que falta às vezes é coisa pouca, é orientação, é ter para onde ir. Pegar os profissionais de saúde para orientar essas pessoas. Dúvidas jurídicas é o que a periferia mais tem, e não tem condições de pagar um advogado. Então a gente quer usar as cozinhas também como um lugar de solidariedade, de acolhimento. A gente quer espelhar nessas cozinhas o mesmo ambiente das cozinhas do MTST, onde as pessoas se sintam à vontade, gostem de estar, um ambiente com harmonia. ${ }^{16}$

Todo o processo é pensado e desenvolvido coletivamente. São os militantes, por meio de mutirões, prática coletiva muito comum no movimento, que preparam os terrenos para a construção das cozinhas ou organizam as reformas necessárias (ver Figura 6). Todos são responsáveis pelo abastecimento das despensas por meio de arrecadações e doações. E há os que cuidam da organização prática desses locais. Como os militantes costumam dizer, são "saídas coletivas" para as necessidades, tornando todos responsáveis pela existência, manutenção e continuidade dos espaços.

\footnotetext{
${ }^{16}$ Informação verbal, em fev. 2021.
} 
Figura 6. Mutirão para construção da cozinha no Rio de Janeiro.

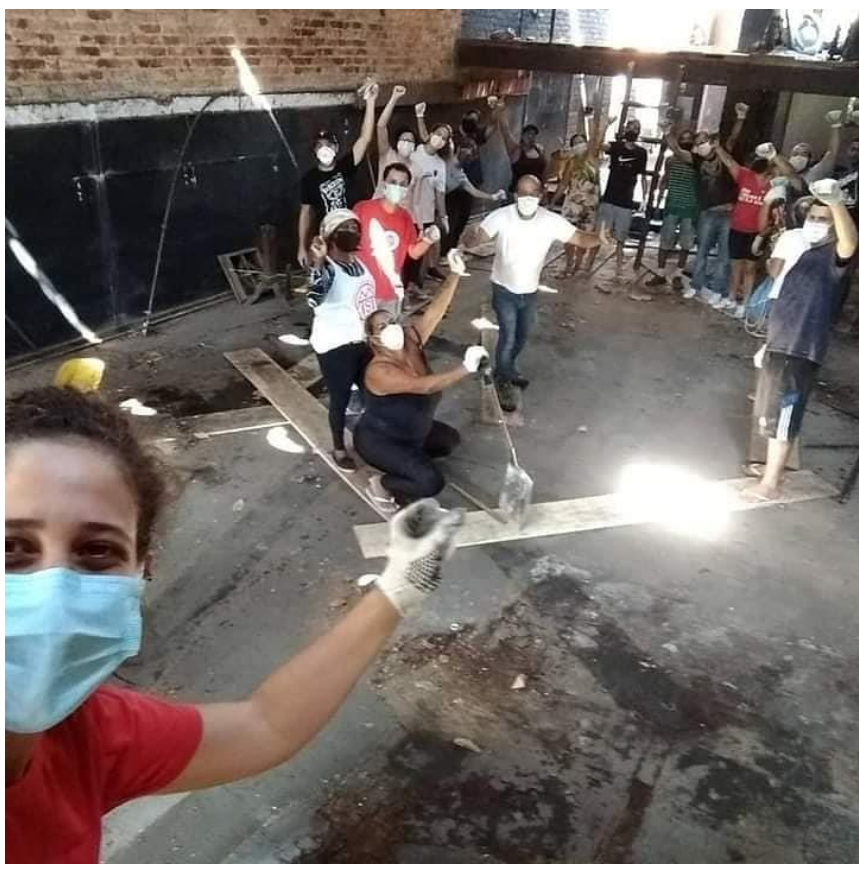

Foto: Acervo MTST (2021).

A primeira fase do projeto, que aconteceu nos meses de março e abril de 202I, teve como meta a inauguração de I6 cozinhas solidárias. Com o êxito desse primeiro momento, o movimento trabalha para inaugurar um total de 26 cozinhas.

\section{Considerações finais}

Um dos motivos que impulsionaram a imediata organização do MTST em torno dessas ações emergenciais, bem como a de diversos outros coletivos e movimentos, foi a inexistência de um programa de Estado que pudesse dar suporte básico aos mais pobres e que consequentemente seriam mais afetados pela crise. Mesmo com a implementação do Auxílio Emergencial, ficou evidente a insuficiência das medidas do governo federal e a dificuldade de alcançar a população mais vulnerável. Então o movimento transformou suas ações em uma campanha com o seguinte lema "movimento social fazendo o que o governo não faz". A capacidade de um governo de responder adequadamente às necessidades da população em um momento de crise não se constrói de um dia para o outro, como ressalta Biroli (2020b). Ela é resultado da história prévia das políticas públicas de saúde, emprego, combate à fome etc.; é condicionada por essa história. No caso brasileiro, os últimos anos foram marcados por retrocessos e extinção de direitos em sequência. É o caso da Reforma Trabalhista, de 2016, e da aprovação da PEC 95/2019, que congelou os gastos públicos. É possível afirmar que Brasil não teve uma política nacional de enfrentamento ao vírus, o que criou uma situação descontrolada em várias partes. Estados e municípios formularam suas políticas com base nas orientações dos comitês 
científicos, no aumento dos números de contágio e de morte, e nas pressões econômicas contra as medidas de isolamento social. Salvo raras exceções, a palavra ineficácia parece boa para definir o conjunto de políticas públicas. Para a aquisição das vacinas, o país assistiu a uma nova sequência de erros pelos quais a população está pagando ao não ter acesso a um número suficiente de imunizantes.

Nos vácuos que se formaram na vida da população, principalmente na parcela mais pobre, surgiram ações solidárias em diferentes esferas - do micro ao macro: das relações entre vizinhos, organizações comunitárias nas favelas a grandes campanhas de arrecadação de alimentos por artistas e movimentos sociais. Em contextos nos quais a atuação do Estado é precária, em que suas insuficiências, nas palavras de Donatella Della Porta (2020), ficaram ainda mais visíveis, como é caso atual, a solidariedade se mostrou fundamental.

Ao analisar a falta de solidariedade entre os indivíduos na contemporaneidade, François Dubet (20I4) aponta que a acentuação da desigualdade social precede uma crise de solidariedade. Para concluir este artigo, compreende-se que no interior dos movimentos sociais, no entanto, outras condicionantes podem fazer a solidariedade aumentar em cenários de extrema deficiência social. Uma delas é a condição fundamental de precariedade que os militantes dividem e que os colocam em um mesmo patamar de necessidade de luta, como apontado também na obra de Judith Butler (20I8). De acordo com essa perspectiva, ainda que as questões sociais tenham impactos diferentes sobre cada um, necessidades e vulnerabilidades partilhadas tornam interdependentes os indivíduos em determinada condição social, o que termina por impulsionar a busca por soluções de forma coletiva e a partir do território das relações. É agir em conjunto quando as condições de ação conjunta estão enfraquecidas ou inexistentes.

Na opinião de Alain Touraine (2020), o que poderá emergir no pós-pandemia será o que se chama de "sociedade de serviços", mas não no sentido da leitura que os economistas fazem. Uma sociedade de serviços entre as pessoas, "entre humanos"', que verá de outra forma aqueles responsáveis pelo cuidado. Como tenho observado ao longo da minha pesquisa de doutorado ${ }^{17}$ esse é um esforço que o Movimento dos Trabalhadores Sem-teto (MTST) realiza no dia a dia, dado que as dificuldades vividas durante a pandemia são também experimentadas, ainda que em outra escala, no cotidiano das periferias brasileiras.

\footnotetext{
${ }^{17}$ Ver nota de rodapé $\mathrm{n}^{\circ} \mathrm{1}$.
} 


\section{Referências}

ALAIN, T. Alain Touraine: "Choque econômico do coronavírus pode produzir reações fascistas". Entrevistador: Marc Bassets. El País, 3I mar. 2020. Disponível em: $<$ https://brasil.elpais.com/ideas/2O2O-O3-3I/alain-touraine-choque-economico-docoronavirus-pode-produzir-reacoes-fascistas.html>. Acesso em: OI abr. 2020.

APPADURAI, A. Gastro-politics in Hindu South Asia. American Ethnologist, v. 8, n. 3, p. 4945II, ago. I98I.

BUTLER, J. Corpos em aliança e a política das ruas. Rio de Janeiro: Civilização

Brasileira, 2018.

BIROLI, F. A tragédia brasileira. Boletim da ANPOCS, n. 8I, Io jul. 2020a. Disponível em: $<$ http://anpocs.org/index.php/publicacoes-sp-2056165036/boletim-cientistassociais/24I2-boletim-cientistas-sociais-n-8I >. Acesso em: I5 jul. 2020.

BIROLI, F. Novo coronavírus, responsabilidade e precariedade. Folha de São Paulo, o8 abr. 2020b. Disponível em: <https://wwwI.folha.uol.com.br/opiniao/2020/o4/novocoronavirus-responsabilidade-e-precariedade.shtml>. Acesso em: 08 abr. 2020.

DELLA PORTA, D. Movimientos sociales en tiempos de Covid-I9: otro mundo es necesario. In: BRINGEL, B.; PLEYERS, G. (Orgs.). Alerta Global. Buenos Aires: CLACSO; Lima: ALAS, 2020.

DUBET, F. La preference pour l'inegalité. Comprende la crise des solidarités. Seuile Republique des Idées, set. 2014.

ESTEVES, U. Solidariedade e gastro-política na pandemia. Boletim da ANPOCS, n. 63, i8 jun. 2020. Disponível em:

$<$ http://anpocs.com/images/stories/boletim/boletim_CS/Boletim_n63.pdf $>$. Acesso em: I4 ago. 2020.

HARVEY, D. Anticapitalismoem tempos de pandemia (pandemia capital). São Paulo: Boitempo, 2020.

SCHERER-WARREN, I. Redes emancipatórias nas lutas contra a exclusão e por direitos humanos. Curitiba: Appris, 2012.

Sites pesquisados:

Movimento dos Trabalhadores Sem-teto(MTST): www.mtst.org

Mapa de conflitos envolvendo justiça ambiental no país:

http://mapadeconflitos.ensp.fiocruz.br/

Olhe para a Fome: http://olheparaafome.com.br/

Freie Universitat Berlin: https://www.lai.fu-berlin.de/ 